\title{
Selected problems on application of steel sandwich panels to marine structures
}

\author{
Janusz Kozak, Assoc. Prof. \\ Gdańsk University of Technology
}

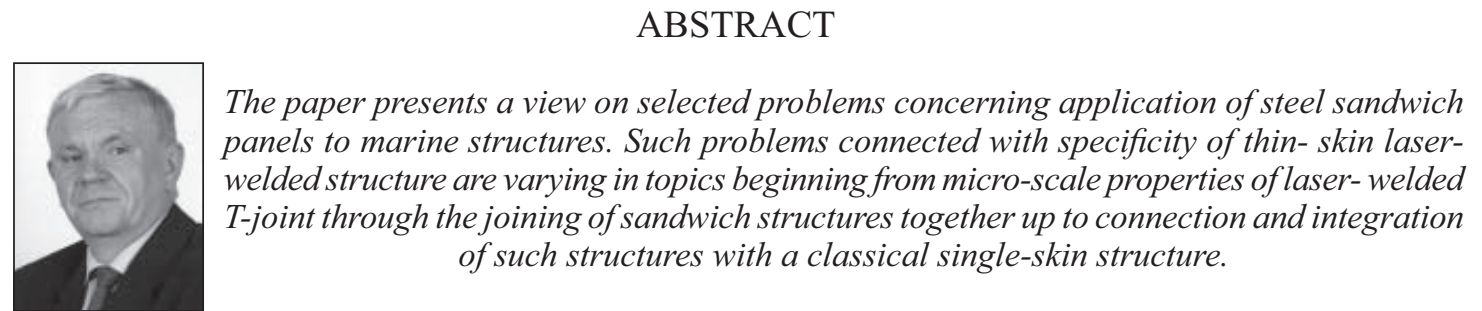

Keywords: laser- welded structures, steel sandwich panels

\section{INTRODUCTION}

Sandwich structures are considered as an optimum design for transferring bending loads and can be either metal structures (built of aluminium skins and honeycomb or metal-foam cores) or polymer structures (built of composite skins and polymerfoam cores).The laser welding technique - a new idea which went out from laboratory testing phase - is currently being applied on industrial scale in shipbuilding. Such technique offers new interesting possibilities because application of the laser - welding creates new opportunities of changing the single-skin configuration typical for ship structure into that of two metal shells connected by internal system of joining and supporting elements, see Fig.1, by application ideas and design

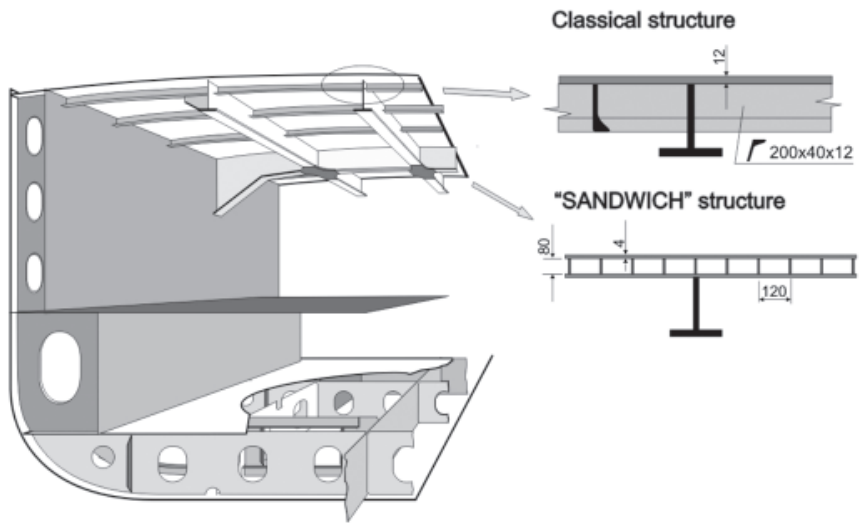

Fig. 1. Example ship deck structure configurations: conventional structure (on the left); I-core-sandwich structure (on the right) solutions which have been reserved so far for glass-reinforced plastic structures.

Such approach offers significantly higher strength properties of cross section of structures in relation to their weight. However the replacement of the "classical" ship hull design consisted of shell plating supported by perpendicular system of heavy stiffeners by such new structure requires knowledge of its characteristics of strength, corrosion, vibration and fire resistance, and also fatigue strength. Moreover the problem of integration of sandwich structures with "classical" ones has to be solved. It concerns joints between sandwich panels themselves as well as between sandwich panels and single- skin structures, outfitting elements (windows, passages), attachment of equipment like cabling, piping etc.

\section{GENERAL IDEA OF SANDWICH STRUCTURES}

Among new materials introduced recently into ship structures, the main light-weight materials used on ships are fibre-reinforced-plastic (FRP) composites and aluminium alloys. The FRP is used in both single-skin and sandwich configurations. Aluminium alloys are commonly found in welded stiffenedplate configurations and in the form of extruded sections (both open and closed), but sandwich arrangements are also possible. High strength steels may also be used to reduce weight, although they are not considered usually to be light-weight materials; they may be found in stiffened-plate configurations and, recently, also in certain sandwich configurations. There is increasing use of mixed solutions in which various materials are combined to form a ship or superstructure. 
Depending on applied materials and sandwich configuration, the following classes of the structure in question can be found:

all- metal sandwich structures whose both skins as well as core is metallic,

semi -steel (hybrid) sandwich structures whose plating is made of a metal but core is non-metallic,

combined steel-plastic sandwich structures in which only certain components are metallic.

The FRP is a composite material widely applied in ship hull structures as the basis for different kind of laminates, but the question what is maximum size of FRP ship hull remains still open. To compare FRP and metal structures such aspects as manufacturing costs, weight, speed, manoeuvrability, maintaining and repairing costs, possible military aspects as well as utilisation costs have to be taken into account [15].

Another idea of sandwich structure presents the concept of Sandwich Plate System (SPS) in which two steel outer skins are connected by means of BASF Inoac elastomer filler. The elastomer core bonded with the steel, acts as a web and provides continuous support to the faces to preclude local plate buckling, and allows this way to eliminate closely spaced stiffeners, though stiffening plates may be added. The flexural stiffness and strength are tailored as required by using appropriate thickness values of the sandwich elements. Some applications of the SPS such as revitalisation of car decks on ferries or repair of FPSO bottom shell plating, were published. As to the latter example the maximum stresses in the damaged bottom plating were reduced by approximately $50 \%$ to satisfy ABS strength requirements, and all hard-point stress concentrations were eliminated [6]. For potential application Limit States Design rules are proposed for innovative bridge decks comprising SPS panels that replace concrete decks [7].

A new hybrid concept of sandwich structures is presented by [13], which consists in combining most of the advantages of metallic and polymer materials while avoiding some of their main disadvantages. For this new concept metal sheets are used at the outer surfaces to maximize rigidity while introducing in between light-weight cores adhesively bonded to keep the whole structure together. Furthermore, composite or wood layers may be used as intermediate layers to improve impact resistance. Potential manufacturing methods for the new structure are based on compression- under- vacuum technique.

Basic type of all-metallic sandwich structures is I-core arrangement which consists of the steel or aluminium panels fabricated as two shell plating of thickness value from 1 to $6 \mathrm{~mm}$ each, with distance between them (height) from 40 to $120 \mathrm{~mm}$, stiffened by one-directional system of stiffeners of 40-120 mm span, connected by using laser welding technique applied from outside of shell plates and creating welded joint through the whole thickness of plate. Application of the sandwich structure instead conventional one (Fig.1), can give about $34 \%$ weight reduction and about $50 \%$ reduction of the manufacturing costs [16].

Steel concrete-filled sandwich structure offers promising properties as it significantly improves strength properties without significant cost increasing. It was also demonstrated that application of low- density covering on outer side of steel sandwich rises resistance to damage resulting from impact transverse load [12].

As bending properties of multilayer thin-skin sandwich structure significantly differ from those of single-shell structure, in the $1950 \mathrm{~s}$ investigations were initiated on theoretical determination of stiffness matrix of sandwich structure [19,
20]. Latest research in this field provides a bending response theory of web-core sandwich plates, consisting in transforming an originally discrete core into an equivalent homogenous continuum forming a sandwich plate, and following thickface-plate kinematics by applying analytical formulation to determine equivalent stiffness properties of the plate. The internal forces and displacements are determined by means of the finite element method solution for a given load and boundary conditions. Thereafter, the periodic structure is reconsidered and the internal forces are used for stress prediction based on analytical formulation [17].

\section{EXAMPLES OF APPLICATION OF METAL SANDWICH PANELS TO MARINE STRUCTURES}

Metal sandwich panels -due to their particular propertiescan be used as structural elements of ship hull smooth, flat surfaces like decks, walls and, in certain cases, side shells, Fig. 2.

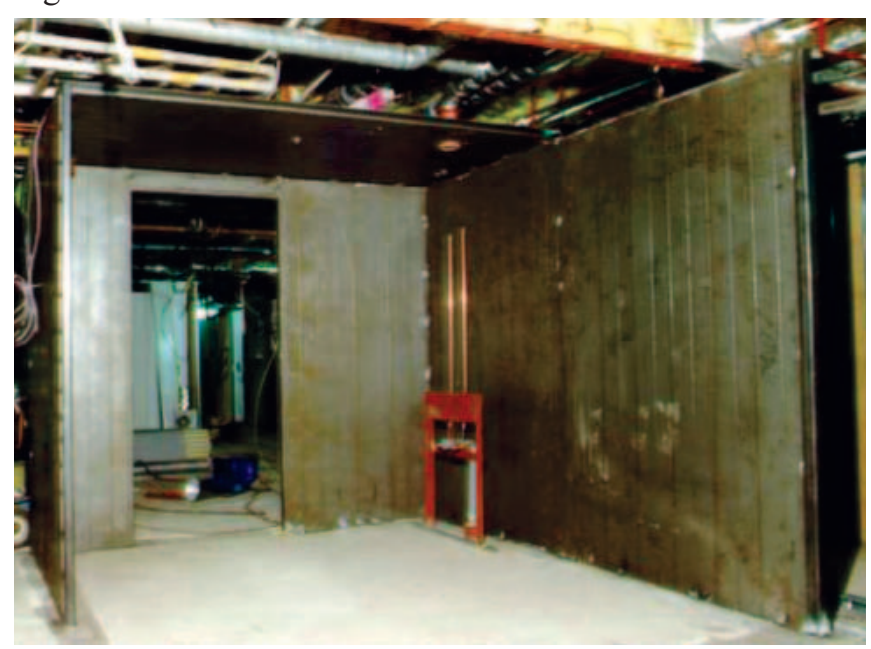

Fig. 2. Internal superstructure walls made of steel sandwich panels (source: Internet)

Another example of sandwich panel application is a RoRo ship's internal ramp - Fig.3. Such structural part of ship is suitable for panel application hence it remains a matter of interest of designers [22].

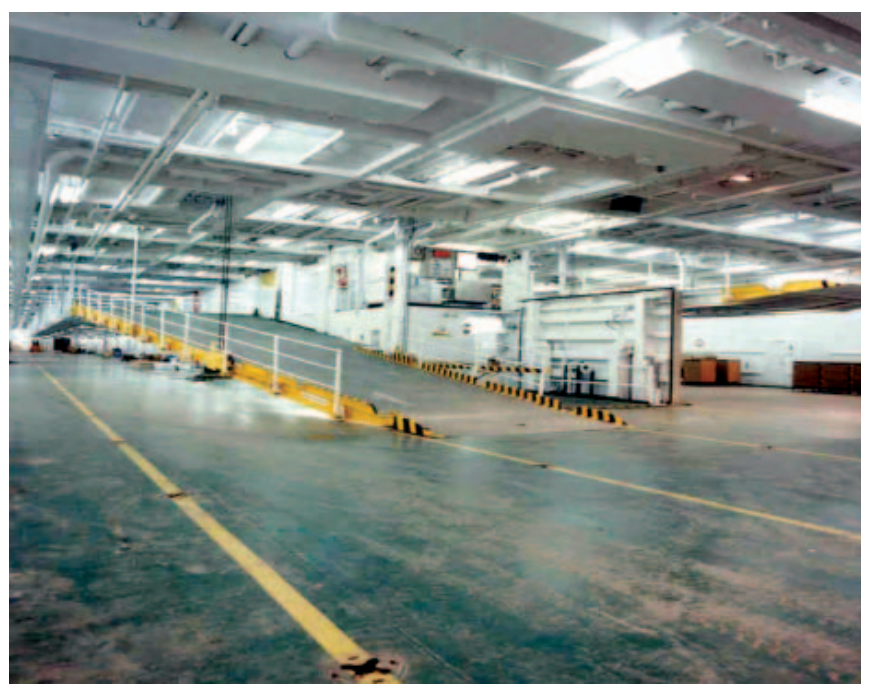

Fig. 3. Ro-Ro ship's internal communication ramp built of steel sandwich panels (source: Internet) 


\section{Specific problems related to steel sandwich panels}

\section{Modelling laser-welded T-joint}

To enable proper modelling of laser -welded steel sandwich panel, a set of methods for generation of its stiffness matrix to reduce amount of model data, is necessary. Meanwhile laser - welded T-joint connecting shell and internal core stiffener, which is present in all steel sandwich panels, significantly differs from conventional MAG -welded fillet joint. Laser - welded joint is formed due to heat generated by light beam acting from outside of shell plate and forming a needle-shape joint from melted metal of joined components. Cross sectional area of such laser weld is significantly smaller than thickness of the joined stiffener. Moreover, regardless of how high quality welding process is, a gap between stiffener and adjacent plate always appears as a result of manufacturing process. A typical cross section of laser-welded T-joint is presented in Fig.4a where the above mentioned properties are also shown. Additionally, a high gradient of hardness distribution due to high intensity of laser light energy during welding process is observed, which suggests presence of local stress concentration due to structural non-homogeneity (Fig. 4b).

a)
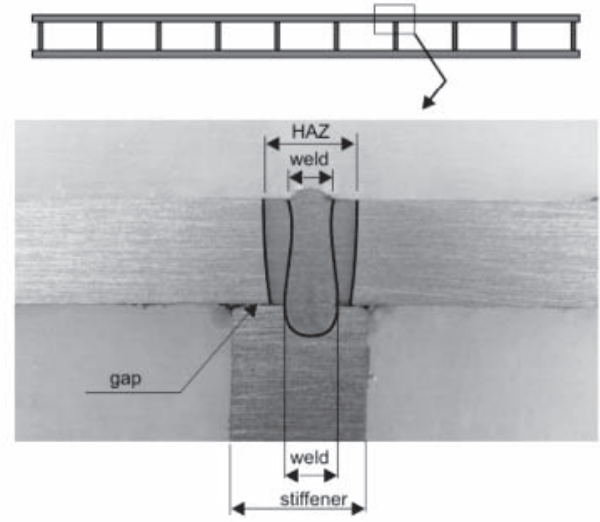

b)

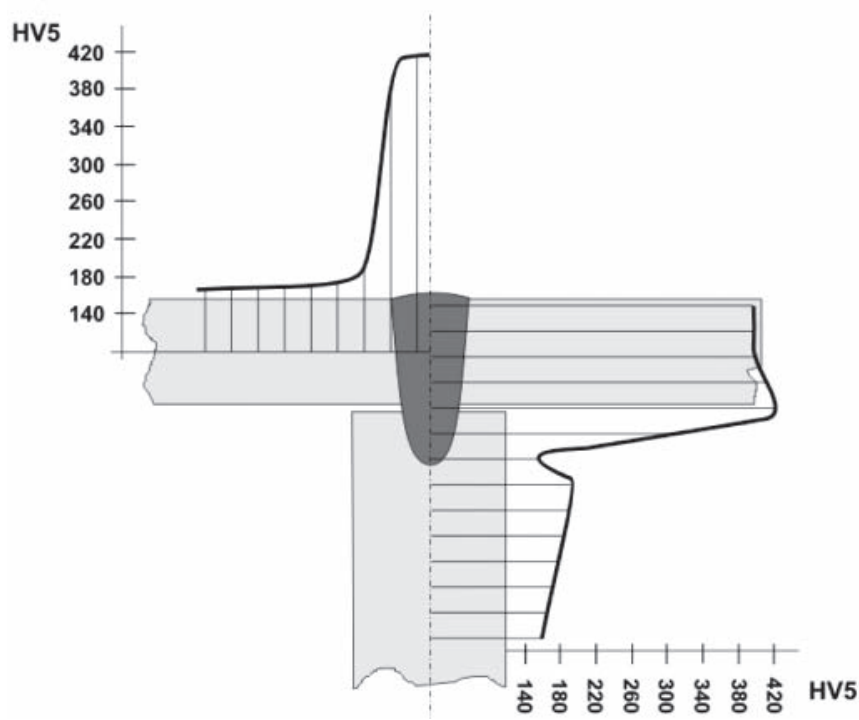

Fig. 4. Properties of laser-welded T-joint:

a) geometry of joint, $\boldsymbol{b})$ distribution of hardness

Such features suggest that the laser - welded T-joint is more sensitive to in-plane bending than ,classical” one. As additional effect of the sensibility the contact processes between faces of stiffener and shell plating can occur. The above mentioned properties suggest radically different fatigue properties as compared to classical T- fillet welded joint.
The transverse dimension of the laser- welded T-joint presented in Fig. 4, is equal to $1.2-1.5 \mathrm{~mm}$ in stiffener face section, whereas the gap between face of stiffener and shell plate is equal to $0.2 \mathrm{~mm}$. The above mentioned peculiarities lead to conclusion that process of the modelling of such geometry by using the finite element method (FEM) for determination of stress distribution, should be carried out on a significantly higher level of details than for classical welded joints. To obtain more detailed information on deformation of joint, investigations for description of deformation field in a laser -welded joint under bending have been carried out. Results obtained from a laboratory - tested specimen by using the laser extensometer technique (LES) confirmed a complex behaviour of the joint under bending load. Apart from tension strain zone also wide compression strain zone occurs. The occurring contact process is responsible also for the shifting of the neutral axis in weld under bending, Fig. $5[1,8]$.

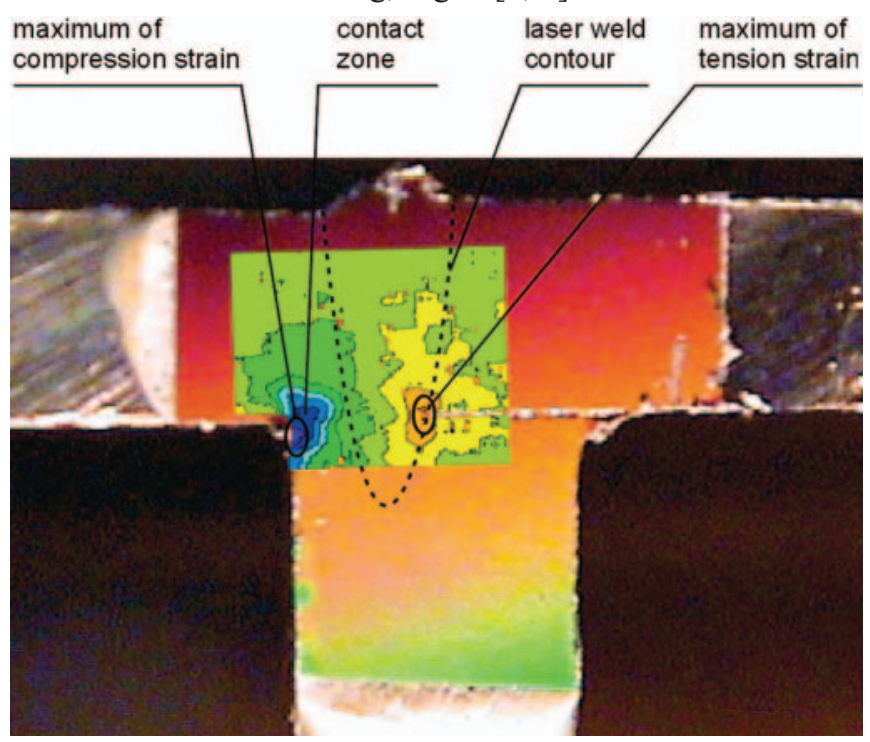

Fig. 5. Strain field in a bended laser-welded joint [1]

Study of the presented strain field distribution shows that due to the contact process the maximum value of compression strain is almost twice higher in relation to that of tension strain [8].

The above mentioned features of the laser-welded T-connection suggest that the proper modelling of its strength behaviour should reflect all the features. The problem leads to studies on the proper modelling of laser weld vicinity with taking into account its stiffness, contact processes as well as material non-homogeneity. Fig. 6 presents the FEM model reflecting the features in question for the joint presented in Fig. $4 \mathrm{a}$.

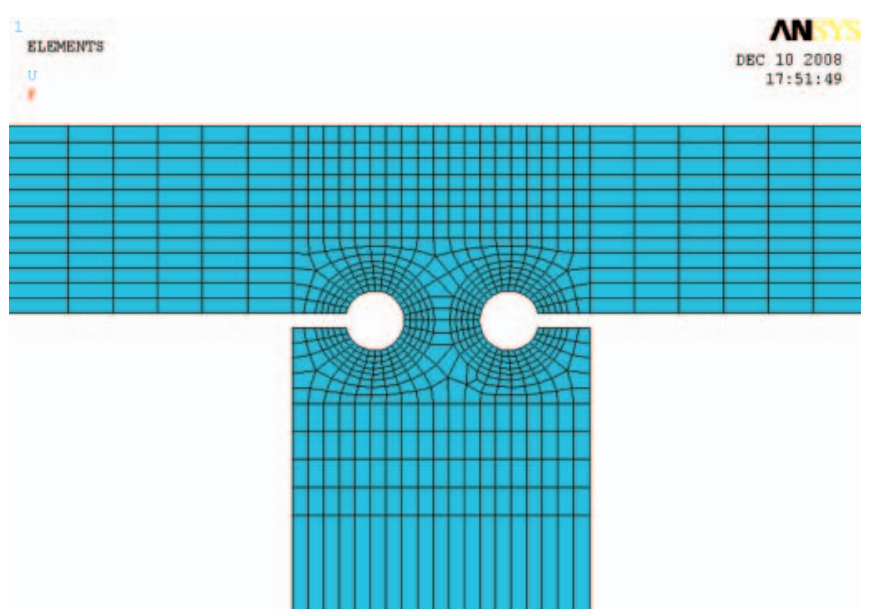

Fig. 6. FEM model of the laser-welded joint [14] 


\section{Joints of sandwich structure}

Connection of the sandwich structure to single-skin structure is one of the important problems to be solved when a sandwich solution has to be applied. In such case the following classes of the problems may be distinguished:

- connection of composite structure to steel single - skin one

- joining steel sandwich panels together

- connection of steel sandwich structure to steel single - skin one

- three dimensional connections.

The use of polymer composites for naval structures is becoming more and more common, particularly due to potential weight savings. It requires to elaborate various kinds of connections between composite structure and steel hull structure. Such connections should be watertight, sufficiently resistant to failure, and, modular panel assembly should be used to make composite-to-metal connection possible. A few different approaches to solving the problem have been presented recently $[2,3]$. Another group of problems is created by the connection between composite panels and supporting steel frames [5].

For all-steel sandwich structure internal joints are necessary because of limited sizes of actually produced panels due to limits of manufacturing lines. The main problem is to maintain continuity of internal stiffener - see Fig. 7. - but appropriate stiffness, water-tightness, manufacturing easiness and low post-welding distortions are also strictly required.
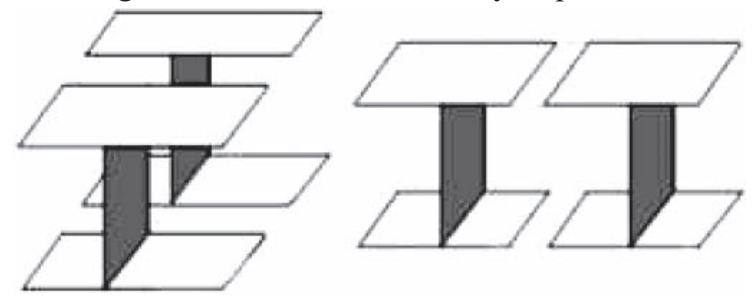

Fig. 7. Scheme of the internal- longitudinal and transverse - joining of metal panels

Possibility of solving a given connection problem depends upon a particular case, but optimisation of a given design from the point of view of stress concentration, weight or manufacturing process is still a subject of research.

For the panel- to- panel connections many proposals can be found depending on given assumptions and limitations. A few possible solutions are presented in Fig. 8.

a)

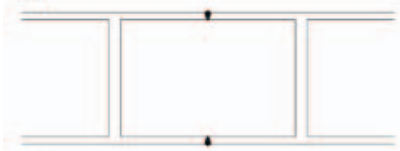

c)

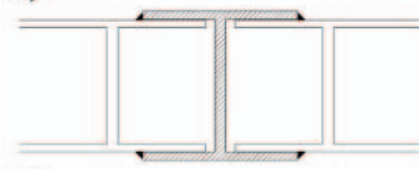

e)

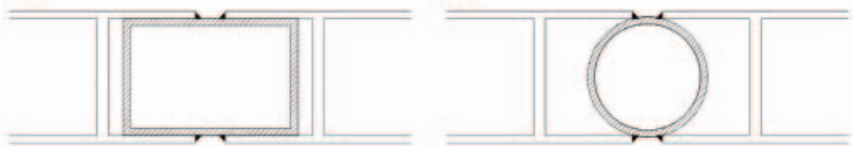

Fig. 8. Selected proposals for panel-to-panel joints [14]

To find the best design as well as optimum geometrical configuration appropriate optimisation procedure is required.
As a target function minimum value of weight or stress concentration factor can be assumed. In Fig. 9 the deformed model of the joint as given in Fig.8b, with indicated vonMisses-stress distribution for the optimum geometrical parameters, is presented.

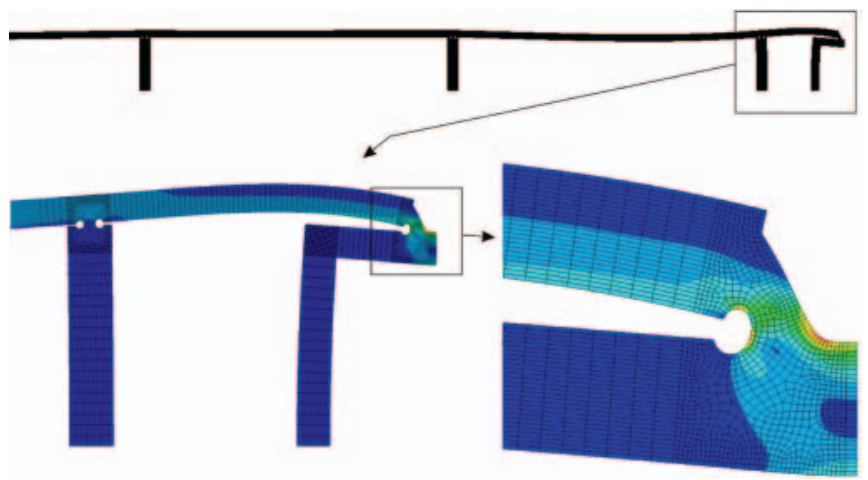

Fig. 9. Deformed model of the joint as given in Fig.8b, with indicated von-Misses-stress distribution for the optimum geometrical design parameters [14]

In the case of angular steel sandwich connection the problem of selection of proper geometry and later - its sizing and then optimisation of the applied design - is additionally complicated by influence of relationship between bending moment and shear force acting in joint area; the obtained results are strongly influenced by this factor $[18,21]$. For the angular connection, apart from its strength properties, manufacturing process is of importance. In Fig.10. two proposals for such joint are presented.
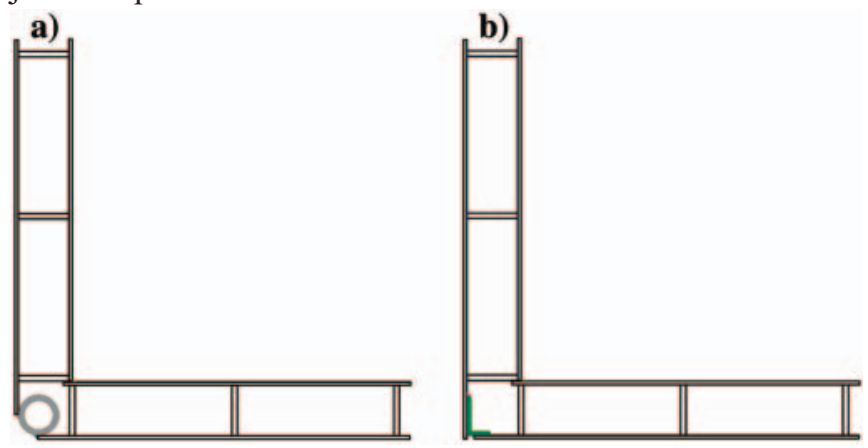

Fig. 10. Selected proposals for angular panel-to-panel joints

For the geometry presented in Fig. 10.b, calculations have been carried out to obtain location and value of the geometric stress concentration factor. The joint deformed under bending moment is presented in Fig. 11, and location of potentially high-stressed area of the joint is shown in Fig. 12.

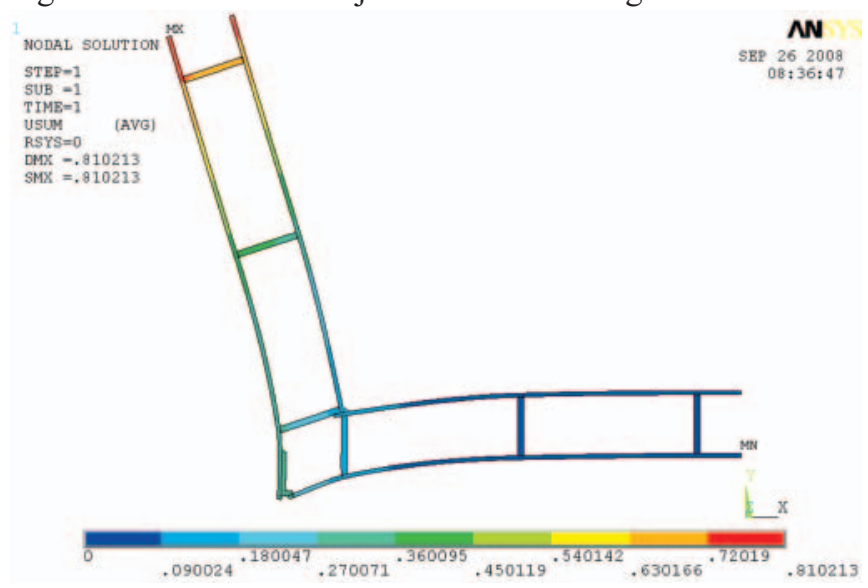

Fig. 11. Angular joint deformed under in-plane bending moment [18] 


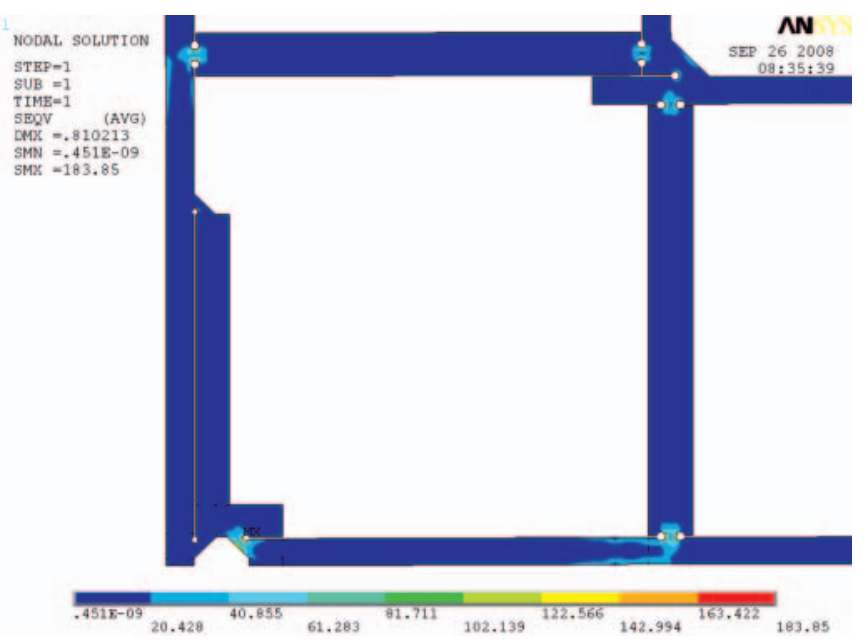

Fig. 12. Detail of high-stressed areas in the joint shown in Fig. 11 [18]

Another problem arises when three sandwich panels have to be mutually connected, for instance, while assembling deck with transverse wall structure - as shown in Fig. 2. Such T-shape connection can be made in a wide variety of geometric forms - depending on strength requirements and manufacturing limitations. Example proposals of such connection are shown in Fig. 13; and example results of calculation of the geometric stress concentration factor are presented in Fig. 14 and Fig. 15.
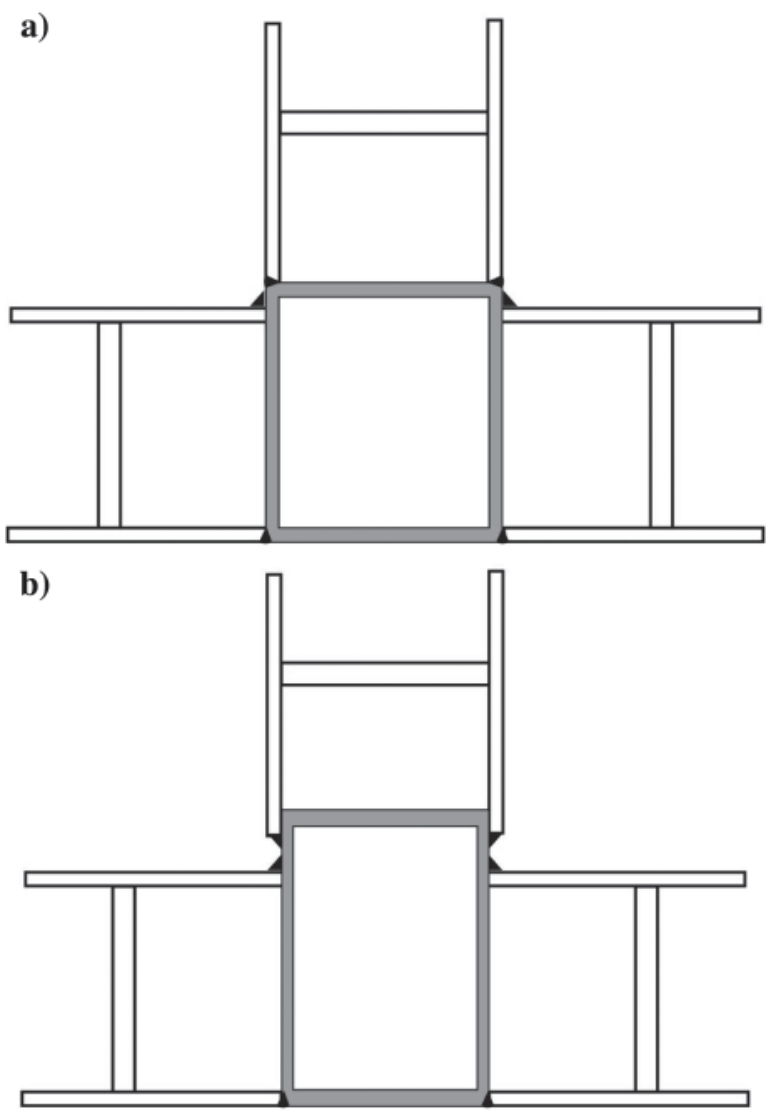

Fig. 13. Proposals for T-connection of sandwich panels [21]

\section{Optimisation of panel structure}

To perform optimisation of the whole structure containing both panel and supporting grillage is common problem when collaboration between stiffeners and panel is necessary. The below presented example was developed on occasion of redesign of a Ro-Ro/car carrier where it was decided that the fixed car decks no. 7 through no. 10 had to be made of steel sandwich panels instead of conventional stiffened ones, which required the sandwich deck load-carrying structure to be optimised. The optimisation was carried out in the following steps:

- optimization of a prototype structure with equivalent beam model for transverses, whereas girders and sandwich panels were modelled as masses;

- optimization of fine models of girder and transverse beam (new beam scantlings - height and width assumed fixed);

- re-optimization of a superstructure module with new scantlings of transverses and under smaller load resulting from lighter girders [22].

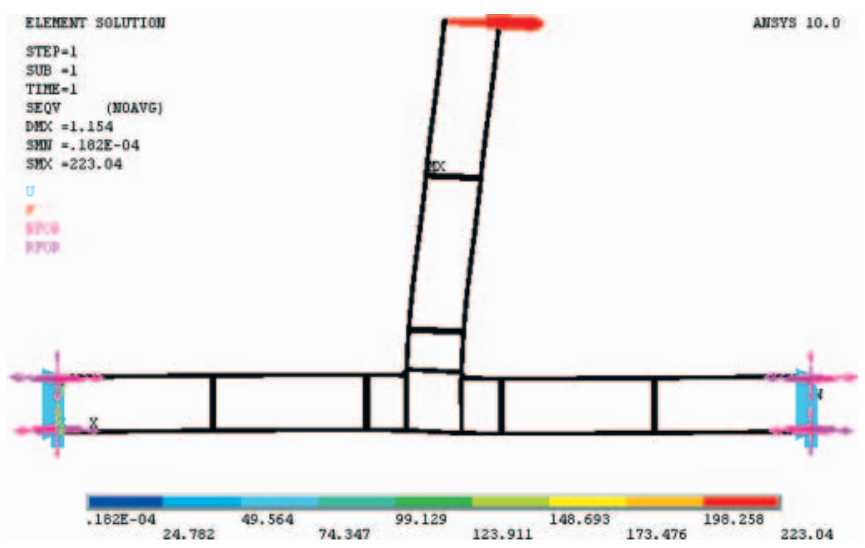

Fig. 14. Deformed FEM model of the joint shown in Fig. 13b [21]

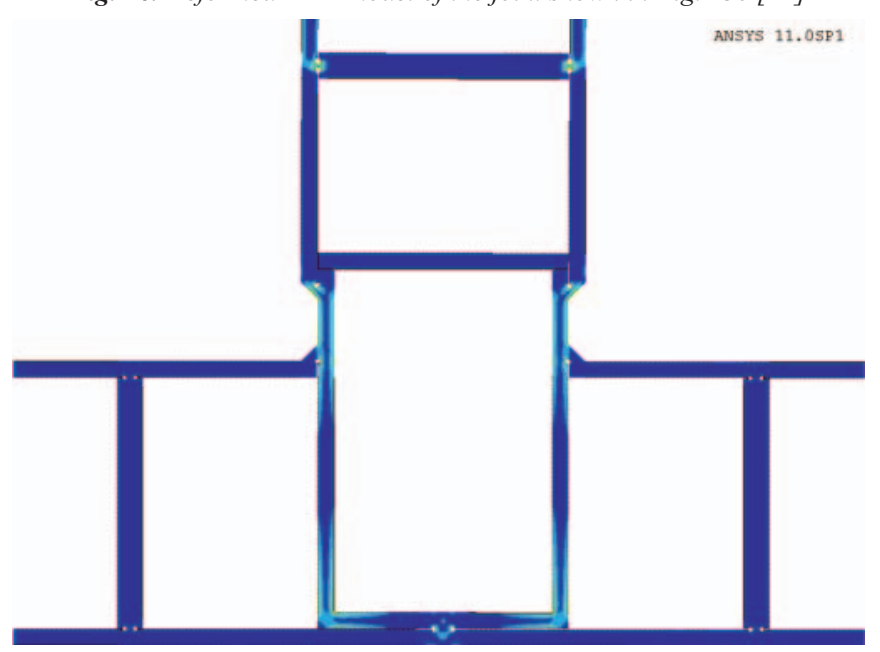

Fig. 15. Detail of high-stressed areas found in the joint shown in Fig. 13b [21]

Flow chart of such procedure is presented in Fig. 16.

\section{AREA OF RESEARCH ON APPLICATION OF STEEL SANDWICH PANELS TO SHIP STRUCTURES}

Possible application of multilayer sandwich panels to hull construction opens prospects for a new generation of ship hull structures. One may say that new philosophy of ship hull design arises. However, before panel structures could be applied, one has to be aware of principles of their behaviour in regions crucial for hull structural safety, namely:

- their mechanical properties under long-term static and variable load, theoretical background for occurring phenomena and principles for their modelling

- progress of corrosion processes in sandwich panels containing metal parts and its influence on their mechanical properties and serviceability 


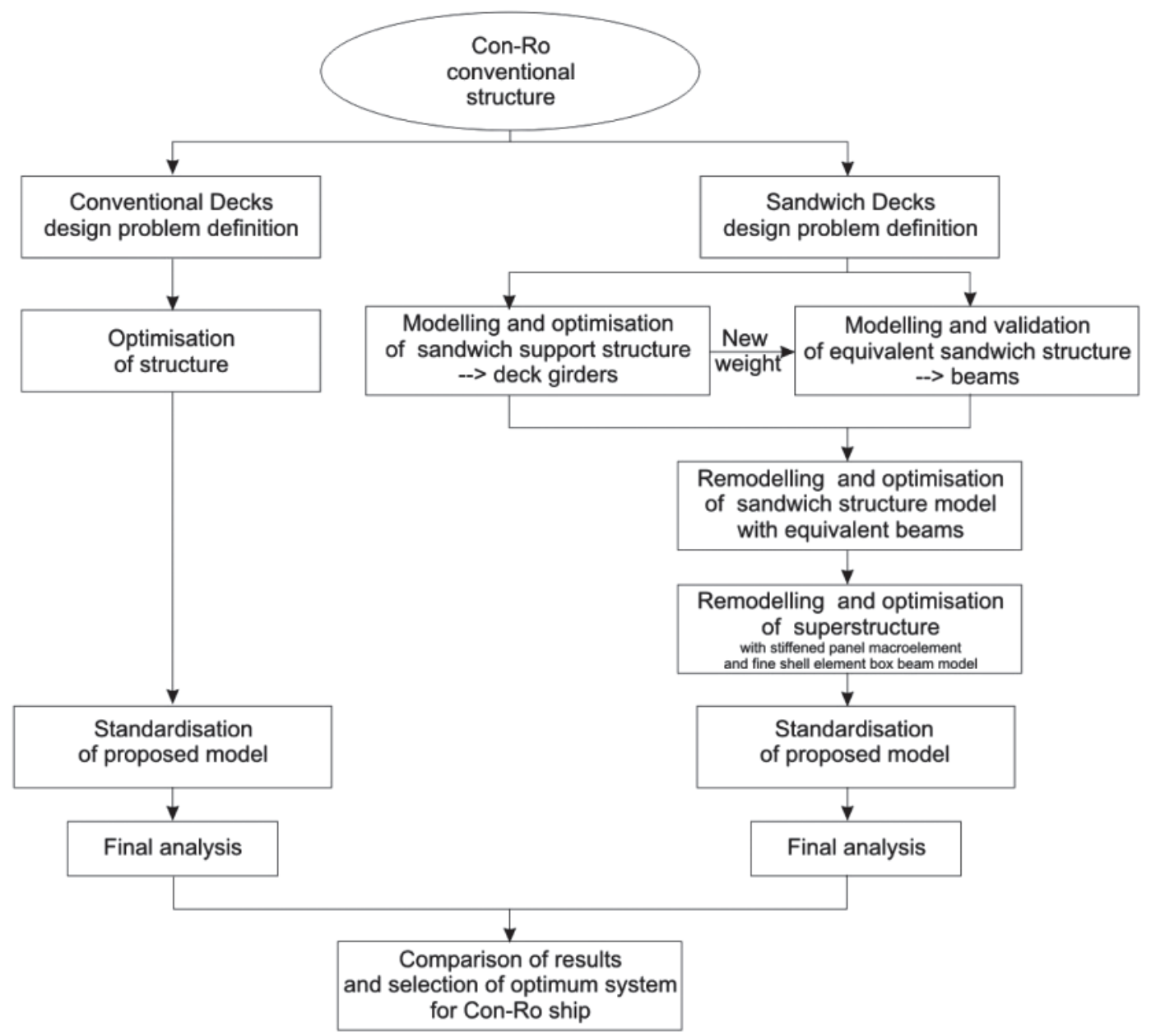

Fig. 16. Flow chart of optimisation procedure of sandwich structure for Ro-Ro car deck [22]

- their vibro-acoustic properties and background for their modelling and forming

- their mechanical properties in elevated and higher temperatures.

Apart from the mechanical characteristics, are also important problems related to manufacturing sandwich panels and mounting them into hull body, such as:

- quality checking procedure of laser welds during manufacturing

- manufacturing tolerances for metal sandwich panels

- strength calculation procedures for joints between sandwich panels themselves as well as between the sandwich panels and classical single-skin structures, including also fatigue life assessment

- design of panel details like passages for cables and pipes, foundations, openings etc.

- assembly procedure for larger structures

- repair procedures

- post-usage utilisation of panels.

\section{FINAL REMARKS}

- The above mentioned problems and many other ones have to be solved to prove safe performance of sandwich consisting structures both in normal and extreme conditions.

- It is necessary to elaborate requirements for application of sandwich structures, written in the form of rules and/or recommended practices, similar to those used for single -skin steel structures. Such rules concerning strictly sandwich structures have not been introduced so far.
- Noteworthy is also the fact that the introducing of sandwich panels into ship structures would change specificity of ship production. Today character of shipyards would be transformed from the manufacturing of steel structures to the assembling of tailored panels produced by highly specialised enterprises and delivered ready for assembling. Such approach would lead to simplification of ship prefabrication processes, reduction of distortions of structures and their assembly time as well as to improvement of manufacturing accuracy.

\section{BIBLIOGRAPHY}

1. Boroński D., Kozak J.: Research on deformations of laser welded joint of a steel sandwich structure model. Polish Maritime Research, No.2, 2004

2. Boyd S.W., Blake J.I.R., Shenoi R.A., Mawella J.: Optimisation of steel-composite connections for structural marine applications. Composites: Part B 39 (2008)

3. Clifford S.M., Manger C.I.C., Clyne T.W.: Characterisation of a glass-fibre reinforced vinylester to steel joint for use between a naval GRP superstructure and a steel hull. Composite Structures, 57 (2002)

4. Internet source: http://sandwich.balport.com; http://www.i-core.com

5. Kabche J.P., Caccese V., Berube K.A.: Structural response of a hybrid composite-to-metal bolted connection under uniform pressure loading. Composite Structures 78 (2007)

6. Kennedy S.J.,, Bond J., Braun D., Noble P.G., Forsyth D.J.: An Innovative "No Hot Work" Approach to Hull Repair on InService FPSOs Using Sandwich Plate System Overlay. 2003 Offshore Technology Conference, Houston, Texas, U.S.A., 5-8 May 2003 
7. Kennedy D.J.L., Ferro A., Dorton R.A.: Tentative Design Rules for Innovative Bridge Decks Comprising Sandwich Plate System Panel. 2005 Annual Conference of the Transportation Association of Canada, Calgary

8. Kozak J.: Strength Tests of Steel Sandwich Panel. Schiffbautechnische Gessellschaft, e.V. Seehafen_Verlag, PRADS 2004

9. Kozak J.: Problems of Assessing Strength Properties of Double Shell, Steel Sandwich Panels. Gdansk University of Technology, Monograph no.65, Gdansk, 2005

10.Kozak J.: Problems of strength modeling of steel sandwich panels under in-plane load. Polish Maritime Research, S1/2006

11.Kozak J.: Fatigue life of steel, laser- welded panels. Polish Maritime Research, S1/2006

12.Kujala P., Klanac A.: Analytical and Numerical Analyses of All Steel Sandwich Panels Under Uniform Pressure Load. Design 2002, Vol. 2, Dubrovnik, 2002

13.Mamalis A.G., Spentzas K.N., Pantelelis N.G., Manolakos D.E., Ioannidis M.B.: A new hybrid concept for sandwich structures. Composite Structures 83 (2008)

14.Niklas K.: Search for optimum geometry of selected steel sandwich panel joints. Polish Maritime Research, No. 2/2008

15.Noury P., Hayman B., McGeorge D., Weitzenbock J.: Lightweight Construction for Advanced Shipbuilding - Recent Development. DNV internal report, 2002

16.Roland F., Metschkow B.: Laser Sandwich Panels for Shipbuilding and Structural Steel Engineering. Meyer Werft, Papenburg, 1997

17.Romanoff J., Varsta P.: Bending response of web-core sandwich plates. Composite Structures 81 (2007)
18.Samluk J.: Numerical analysis of angular sandwich-sandwich panel connection. M.Sc. Thesis, Gdansk University Technology, Faculty of Ocean Engineering and Ship Technology, 2008, unpublished

19.Tat-Ching Fung et al: Shear Stiffness for C-core Sandwich Panels. Journal of Structural Engineering. August 1996

20.Lok T.S., Cheng O.H.: Elastic Stiffness Properties and Behaviour of Truss-core Sandwich Panels. Journal of Structural Engineering, May 2000

21.Zaremba M.: Analysis of the concentration coefficients in Tconnections of the sandwich panels. M.Sc. Thesis, Gdansk University Technology, Faculty of Ocean Engineering and Ship Technology, 2008, unpublished

22.Zanic V., Andric J., Stipcevic M., Prebeg P., Hadzic N.: Structural Optimization of a Sandwich Car Deck Structure For Ro/Ro Car Carrier from Uljanik Shipyard. The $18^{\text {th }}$ Symposium on Theory and Practice of Shipbuilding - SORTA 2008. Pula, 16 -18 October 2008.

\section{CONTACT WITH THE AUTHOR}

Janusz Kozak, Assoc. Prof. Faculty of Ocean Engineering and Ship Technology,

Gdańsk University of Technology Narutowicza 11/12 80-952 Gdańsk, POLAND e-mail:kozak@pg.gda.pl 